\title{
IMPLEMENTATION OF QUALITY CONTROL IN NEWSPAPER PRINTING COMPANIES
}

\section{PENERAPAN QUALITY CONTROL PADA PERUSAHAAN CETAK KORAN}

\author{
Lala Hucadinota Ainul Amri ${ }^{a^{*}}$, Yunus Fitriadi ${ }^{a}$, Achmad Firdaus Putra Pradissa ${ }^{\text {a }}$ \\ a Teknik Grafika, Politeknik Negeri Media Kreatif, Indonesia \\ *Email: lalahuca@polimedia.ac.id
}

\begin{abstract}
Newspaper printing production processes cannot be separated from the problems that affect printed results and excessive waste. So in a printing company, quality control is needed in order to get good printing results and minimize the amount of waste. The print quality results in a company have several shortcomings such as unsuitable colors, and difficulty to get the register when printing. Apart from the aforementioned shortcomings, there are also factors that cause excessive waste, namely scumming, register disturbances, not sharp printouts, set-off, ghosting, and broken paper. How to solve problems that affect print quality and excess waste by cleaning the ink roll, adjusting the leg according to the proof, adjusting the pressure cylinder pressure, and adjusting the volume of wetting water. From the problems found, the print quality results in a printing company need to be increased so that the amount of waste generated is not too much or too much.
\end{abstract}

\section{Keywords-Print Quality, Waste, Quality Control}

\begin{abstract}
Abstrak- Proses produksi cetak koran tidaklah lepas dari permasalahan yang mempengaruhi hasil cetakan dan limbah buangan yang berlebihan. Maka dalam suatu perusahaan percetakan diperlukan pengendalian mutu atau Quality Control guna mendapatkan hasil cetakan yang baik dan meminimalisir jumlah waste. Hasil kualitas cetakan di suatu perusahaan memiliki beberapa kekurangan seperti warna tidak sesuai sesuai, dan sulit mendapatkan register pada saat mencetak. Selain beberapa kekurangan tadi adapun faktor yang menyebabkan limbah buangan berlebihan yaitu scumming, gangguan register, hasil cetakan tidak tajam, set-off, ghosting, dan kertas putus. Cara mengatasi permasalahan yang mempengaruhi kualitas cetakan dan limbah berlebih dengan cara membersihkan roll tinta, setel aanleg sesuai dengan proof, mengatur tekanan sillinder tekan, dan mengatur volume air pembasah. Dari permasalahan yang ditemukan hasil kualitas cetakan di suatu perusahaan cetak perlu
\end{abstract}


ditingkatkan agar jumlah limbah buangan yang dihasilkan tidak terlalu banyak atau berlebih.

Kata Kunci- Kualitas Cetak, Limbah, Quality Control

\section{PENDAHULUAN}

Komunikasi Grafika adalah

komunikasi yang dilakukan melalui media cetak dimana informasi yang akan disampaikan kepada komunikan disajikan dalam bentuk tulisan, gambar atau ilustrasi yang diatur sedemikian rupa sehingga memiliki nilai estetika dan dapat menarik perhatian. Untuk menarik perhatian para pembaca, informasi yang disampaikan disajikan secara bervariasi yang salah satunya adalah cetakan berwarna. Karena biasanya pembaca akan tertarik pada cetakan yang berwarna.

Proses penyampaian pada bidang grafika, kualitas setiap cetakan harus sangat diutamakan, karena bila salah satu yang menunjang faktor tersebut kurang, maka akan sangat mempengaruhi terjadinya proses komunikasi yang ideal. Kualitas yang dituntut oleh pemesan haruslah terpenuhi, sebab jika tidak terpenuhi mereka menginginkan cetak ulang dan merupakan kerugian bagi pemesan dan juga perusahaan. Selain biaya produksi yang harus ditanggung, juga dapat mempengaruhi citra percetakan dan mempersempit untuk mendapatkan order dari pemesan.

Mencegah agar tidak terjadi hal tersebut, perlu penanganan QC (Quality Control) dalam menangani berapa kemungkinan berkurangnya kualitas, melakukan persiapan cetak secara terencana. Karena bila kualitas hasil cetakan dapat ditingkatkan berarti dapat meningkatkan pula produktivitas dan efisiensi dalam penggunaan bahan, mengurangi biaya produksi serta meningkatkan tingkat kepuasan pelanggan terhadap hasil cetakan yang dihasilkan.

Pada saat melakukan penelitian dan pengambilan data ini, peneliti berkesempatan untuk mendampingi Praktik Industri di PT yang terletak di daerah Pulogadung, Jakarta Timur yaitu PT. Aksara Grafika Pratama, bergerak didalam dunia percetakan yang dimana produk yang dicetak diantaranya seperti Majalah, Buku Partai, Koran, Buku Pelajaran, Kalender dll. Dalam hal ini peneliti memilih PT. Aksara Grafika Pratama sebagai sample dan digunakan sebagai acuan perusahaan percetakan koran yang menerapkan Quality Control secara ketat.

\section{METODE}

Metode yang digunakan dalam penelitian ini adalah metode Kualitatif, dengan berbagai pendekan dan dijelaskan secara rinci sebagai berikut : 


\section{A. Metode Observasi Lapangan}

Metode ini dilakukan dengan melihat langsung proses produksi pada saat melakukan praktik industri.

B. Metode Kepustakaan

Metode ini dilakukan dengan mencari dan mengumpulkan data dari berbagai sumber seperti buku, artikel, majalah, internet atau sumber informasi lainnya yang berkaitan dengan pembahasan.

C. Metode Wawancara

Wawancara adalah teknik pengambilan data dan informasi dimana penulis langsung berdialog dengan responden untuk menggali informasi dari responden.

\section{HASIL DAN PEMBAHASAN}

Setelah peneliti melakukan penelitian di perusahaan sample mendapatkan kualitas cetakan iklan koran memiliki beberapa permasalahan yang mengganggu hasil cetakan. Produksi rusak merupakan masalah yang pasti terjadi, kerusakan yang terjadi biasanya kesalahan yang disebabkan oleh tenaga kerja yang mengoperasikan mesin ataupun mesin itu sendiri. Bagian Produksi menyebut bahwa produksi yang rusak dinamakan miss print atau salah cetak yang dimana ini terjadi akibat beberapa faktor.

Beberapa faktor yang menyebabkan kerusakan pada proses produksi yang masih perlu menjadi perhatian pihak percetakan.
Berikut beberapa kegiatan dalam proses produksi yang telah dilakukan oleh pihak percetakan perusahaan dalam upaya pengendalian kualitas produksi dan beberapa hal yang menjadi kelemahan proses produksi yang dapat mempengaruhi kualitas cetak, yaitu:

\section{A. Material}

Dalam proses cetak koran, material merupakan faktor penting dalam kualitas produksi. Mulai dari kertas, tinta, air pembasah dan lain-lain. Perusahaan dalam memesan bahan baku yang digunakan untuk proses percetakan menggunakan bahan baku/material yang sudah memenuhi standar yang baik.

\section{B. Tenaga Kerja atau Man}

Untuk mengendalikan kualitas produksi, pihak kepala produksi turun langsung di lapangan dalam melakukan pengawasan dan pengendalian terhadap pekerja-pekerja produksi. Hal ini dilakukan agar dapat mencegah terjadinya kerusakan produksi yang tinggi serta dapat mencegah terjadinya pemborosan dan selalu mengusahakan penghematan.

Pengontrolan dilakukan setiap hari oleh kepala produksi percetakan, dengan memberikan arahan apabila ada pekerja yang salah dalam melaksanakan tugasnya masingmasing. Tenaga kerja dalam hal pemenuhan kebutuhan, beberapa didapat dari pelajar 
SMK yang melakukan magang disana dan kemudian dijadikan pegawai, sehingga tenaga kerja tersebut sudah terbiasa bekerja dan dapat berkomunikasi satu sama lain dengan baik. Hal ini membuat kerja sama tim dalam suatu produksi menjadi terpadu.

Pihak percetakan juga memberikan diklat kepada pekerja-pekerja yang baru masuk agar nantinya mempunyai pengalaman yang lebih dalam bidang percetakan, seperti studi banding ke percetakan-percetakan yang sudah maju.

C. Metode atau prosedur produksi cetak

Permasalahan yang sering terjadi pada hasil cetakan saat proses cetak koran ini adalah metode atau alur dalam proses pencetakan. Hal ini sering terjadi pada saat proses produksi koran dimulai di dalam menentukan baik atau tidaknya suatu cetakan. Prosedur produksi cetak sangat diperhatikan agar hasil cetakan baik dan sesuai dengan keinginan customer. Mulai dari order kerja, persiapan mesin, persiapan kertas atau bahan, pengawasan hingga proses sortir.

D. Mesin

Dalam pengendalian proses produksi yang sangat berperan penting adalah mesin cetak yang dapat menimbulkan kerusakan produksi yang sangat tinggi, maka dari itu pihak percetakan menempatkan seorang tenaga ahli yang sangat berpengalaman di bidang mesin cetak. Disamping itu juga sebelum diadakannya proses mencetak majalah atau buku yang akan dicetak operator memeriksa terlebih dahulu mesin yang akan digunakan untuk mencetak, seperti pemberian oli, pengecekan setting, pembersihan bagianbagian mesin yang kena rembesan tinta dan lain-lain.

Berikut adalah beberapa penyebab yang dapat mempengaruhi hasil kualitas cetakan yang dijelaskan dalam Fishbone Diagram pada 7(seven) Basic Quality Tools: 


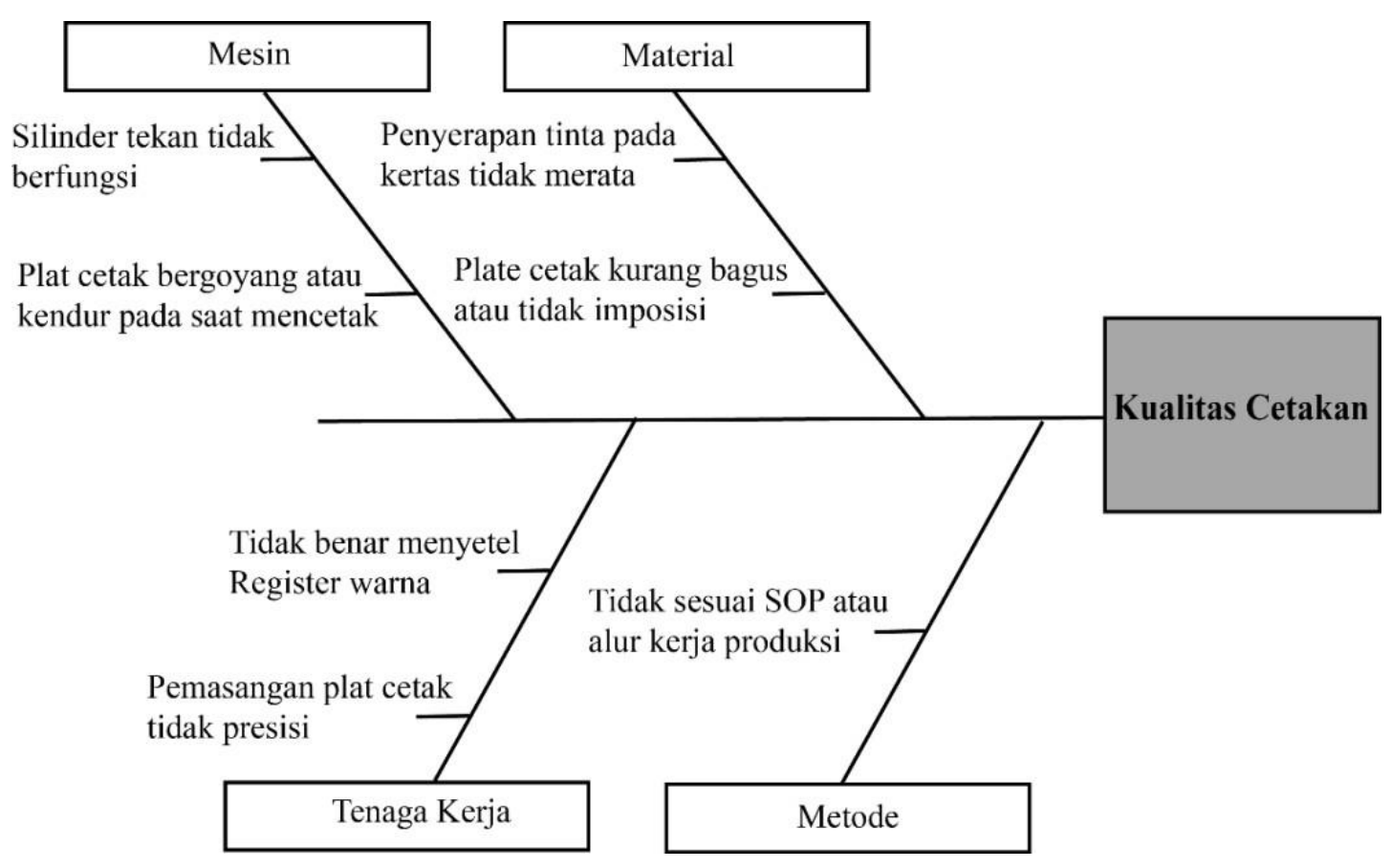

Gambar 1. Fishbone Diagram Kualitas Cetakan

Permasalahan Yang Terjadi Pada Proses Cetak Koran, pada saat melakukan proses produksi cetak Koran, bagian produksi selalu dihadapkan dengan berbagai permasalahan cetak. Permasalahan tersebut tergantung dari beberapa faktor, operator pun mempunyai istilah- istilah tersendiri dalam menamai permasalahan tersebut. Permasalahan tersebut juga diselesaikan sesuai cara dan keahlian masing-masing operator produksi.

Selain pada proses cetak faktor pada bagian pra-cetak juga mempengaruhi dalam proses produksi cetak Koran. Berikut beberapa permasalahan dan solusi yang dialami peneliti dengan mengobservasi langsung saat mencetak koran:

1. Bagian pra cetak a. Plat cetak tidak baik atau imposisi kurang presisi. Cara mengatasinya : ganti dengan yang baru

b. Layout pada proses pembuatan plat cetak terjadi kesalahan. Cara mengatasinya : imposisi pada pembuatan layout lebih diperhatikan

c. Kurangnya pengecekan saat plat cetak akan diserahkan ke bagian cetak Cara mengatasinya : harus teliti dan di cek terlebih dahulu sebelum diserahkan

2. Bagian cetak

a. Scumming atau cetakan kotor

Scumming yaitu permasalahan cetak yang dimana tinta cetak ikut tercetak pada plate yang tidak bergambar atau juga area yang non image yang harusnya bersih malah 
terkontaminasi atau ikut tecetak. Hal ini disebabkan karena area pelat cetaknya mulai menyerap tinta dan menolak air pembasah.

Beberapa hal penyebab terjadinya scumming:

1) Tinta terperangkap pada roll larutan air pembasah.

2) Tekanan cetak terlalu tinggi.

3) $\mathrm{pH}$ air pembasah tidak seimbang, kemungkinan terlalu tinggi atau terlalu rendah.

4) Roll larutan air pembasah kurang baik, settingnya seperti terlalu ketat atau sudah haus penutupnya.

5) Blanket tidak ketat saat terpasang di silinder

Menghindari atau mengatasi masalah scumming:

1) Bersihkan atau rekondisi roll tinta

2) Atur tekanan roll pembasah atau cuci bersih dan bila perlu ganti lapisan penutup roll (jika terjadi kerusakan yang parah).

3) Atur $\mathrm{pH}$ air pembasah dengan seimbang, sekitar 4-4.5

4) Atur pemakaian tinta sesuai kebutuhan

b. Gangguan Register

Untuk menghasilkan kualitas cetakan yang baik, maka register cetakan pun harus diperhatikan juga agar memenuhi kriteria dan persyaratan teknis. Karena kualitas cetakan yang baik ditentukan oleh register yang sesuai, oleh karena itu toleransi register pada cetakan Koran $0,25 \mathrm{~mm}$ masih terlihat baik.

Beberapa hal yang menjadi penyebab:

1) Timing aanleg tidak tepat terhadap kertas

2) Aanleg depan miring posisinya

3) Sepatu aanleg atau alasnya tumpul

4) Timing antara aanleg samping dengan silinder gripper tidak tepat

5) Gigitan gripper tidak merata Gripper bengkok atau rusak Menghindari atau mengatasi masalah:

1) Setel aanleg depan agar pada saat kertas dijepit gripper dan mulai maju, aanleg depan sudah naik \pm $0,5 \mathrm{~mm}$

2) Posisi aanleg harus sejajar, bila diubah untuk penyetelan harus dikembalikan lagi pada saat ganti plate baru

3) Ganti yang baru

4) Saat aanleg samping melepas kertas, gripper harus terbuka

5) Setel gripper supaya rata, bila kesulitan sebaiknya panggil teknisi

6) Perbaiki atau ganti yang baru

c. Hasil cetakan tidak tajam Hasil cetakan yang bersih dan 
tajam dapat dihasilkan dengan kecermatan yang tinggi dalam pemilihan bahan yang tepat serta memperhatikan perawatan pada mesin, agar hasil cetakan sesuai dengan proof yang ada.

Beberapa hal yang
mempengaruhi:

1) Tekanan cetak tidak tepat

2) Setelan air pembasah tidak sesuai

3) Blanked kendur atau tidak baik

4) Plat cetak kurang baik

Menghindari atau mengatasi masalah:

1) Tambah atau kurangi tekanan pada silinder tekan, terhadap silinder blanked

2) Jangan sekali-kali mencetak dengan air berlebihan

3) Kencangkan atau ganti baru

4) Ganti plat baru

d. Set-off

Set-off terjadi ketika tinta menjiplak ke bagian sisi kertas yang lain atau mengenai permukaan cetakan yang lain karena tinta belum mongering (daya serap rendah).

Beberapa hal penyebab terjadinya:

1) Terlalu banyak tinta cetak di atas kertas terlalu tebal

2) $\mathrm{pH}$ air (dampening solution) terlalu asam
3) Tidak cocok noda warna tinta cetak

4) Sifat lapisan kertas tidak baik (coating)

5) Terlalu banyak menumpuk hasil cetakan

6) Terjadi elektrisitet statis, maka kertas saling menarik

7) Spray powder tidak tertabur dengan baik/tidak keluar

Menghindari atau mengatasi masalah:

1) Mencetak secara tipis atau menggantitinta cetak yang berkepekatan tinggi.

2) Kontrol $\mathrm{pH}$ air diantara $\mathrm{pH}$ 5.06.5 .

3) Memeriksa noda warna tinta cetak dan mengganti tinta cetak yang cocok

4) Sedikit-sedikit saja menumpuk hasil cetakan, atau memakai papan di antara hasil cetakan

5) Menyiramair di tempat kerja untuk mencegah terjadinya elektrisitet statis.

6) Memeriksa alat tabur spray powder

e. Ghosting atau cetakan berbayang

Penyebab terjadinya cetakan berbayang, umumnya ditandai dengan suatu area kecil cetakan yang berwarna solid tercetak sebelum atau 
sesudah area cetak yang berwarna solid lebih besar. Dimana area cetak berukuran kecil tersebut mencuri atau mengambil warna tinta dari rol cetak berarea jauh lebih besar dengan warna solid pula.

Beberapa hal penyebab terjadinya cetakan berbayang:

1) Tinta terlalu encer atau terlalu tipis saat tercetak

2) Terlalu banyak larutan pembasah yang digunakan

3) Setingan rol cetak ke plat cetak kurang atau tidak pas dan terkadang terlalu ketat atau terlalu longgar

Menghindari atau mengatasi masalah:

1) Cetak dengan menggunakan minimum larutan pembasah

2) Setting ulang antara rol cetak dengan plat cetak menggunakan strip yang pas

f. Kertas putus

Setiap kali mencetak koran pasti permasalahan ini sering timbul di percetakan manapun, karena banyak penyebab permasalahan kertas putus terjadi

Beberapa hal penyebab terjadinya cetakan berbayang:

1) Air pembasah yang masuk terlalu banyak
2) Bak air pembasah ada yang menetes

3) Angin di reelstand terlalu kencang

4) Tekanan pada silinder tekan terlalu besar

Menghindari atau mengatasi masalah:

1) Cek apakah ada air yang menetes di bak air

2) Cek dan kurangi angin di reelstand

3) Kurangi tekanan pada silinder tekan

Pengaruh Permasalahan Cetak Yang Terjadi Pada Proses Produksi Koran. Dalam proses produksi pasti ada masalah yang terjadi yang menghambat waktu proses produksi cetak berlangsung. Saat dilakukan proses cetak terdapat banyak hambatan seperti, scumming, ghosting, gangguan register, dan hasil cetakan tidak tajam. Selain hambatan proses cetak tenaga kerja dan mesin pun dapat berpengaruh dalam waktu proses cetak. Maka dari itu proses cetak Koran harus diperhatikan dari segala faktor agar proses cetak berjalan dengan baik dan benar, dan juga harus konsisten sesuai jadwal agar dapat meminimalisir kesalahan supaya tidak membuang-buang waktu proses cetak.

Bagian pra cetak juga berpengaruh dalam waktu proses produksi cetak berlangsung. Bagian pra cetak terdapat hambatan juga seperti, plat cetak rusak atau tidak baik, layout 
pada plat salah dan waktu pembuatan plat terjadinya beberapa permasalahan yang yang terlalu lama karena menunggu redaksi. berpengaruh terhadap waktu proses cetak:

Berikut adalah Fishbone Diagram penyebab

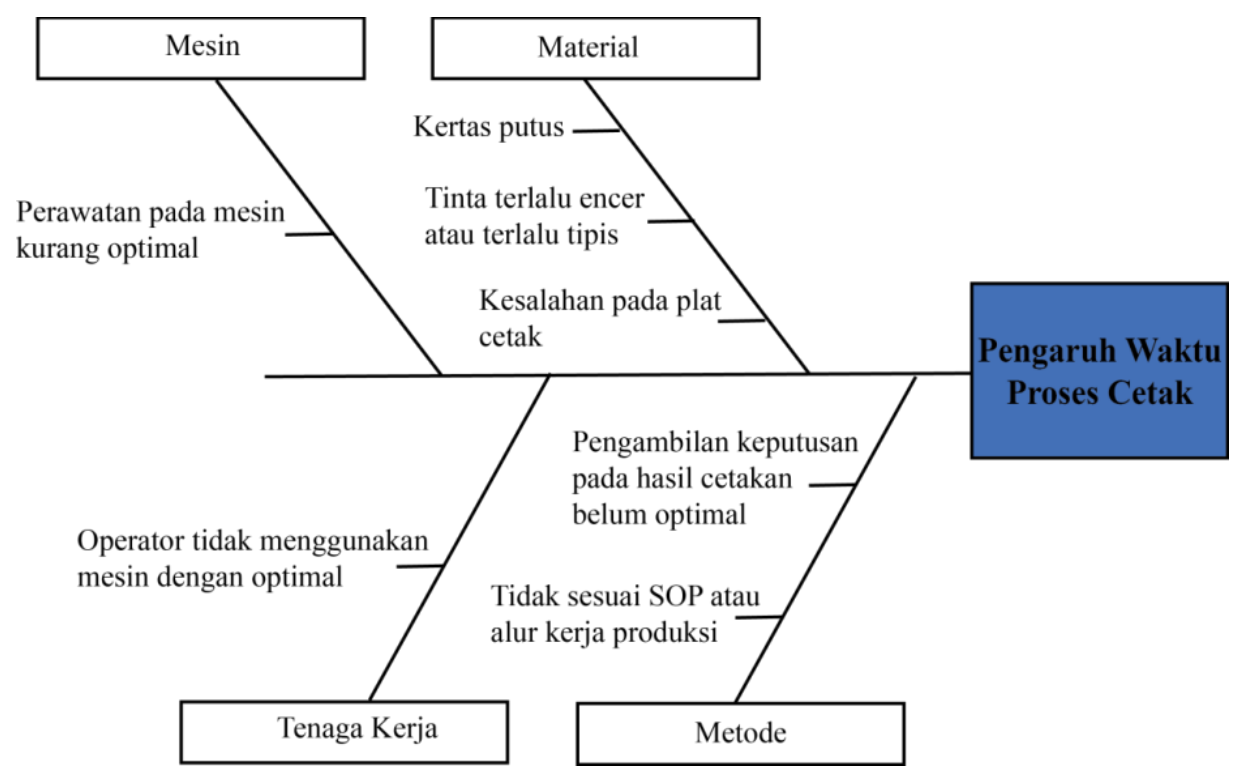

Gambar 2. Fishbone pengaruh terhadap waktu proses cetak

A. Pengaruh Terhadap Waste atau Sampah Cetakan

Banyak terjadi permasalahan pada proses cetak Koran Bisnis Indonesia dan menyebabkan banyaknya waste. Dalam hal ini juga berdampak pada jumlah pemakaian bahan baku yang telah ditetapkan, oleh karena itu pentingnya perhatian dan pengendalian mutu atau quality control pada bagian pracetak dan cetak Koran agar dapat meminimalisir kesalahan cetak yang membuat waste cetakan tidak terlalu banyak. Berikut adalah Check Sheet jumlah waste pada minggu ke pertama Praktik Industri berdasarkan jenis atau permasalahan yang ditimbulkan. 
Vol. 6, No. 2, Oktober 2019, hal. 84-95

Tabel 1. Jumlah Waste Minggu ke pertama

\begin{tabular}{|c|c|c|c|c|c|c|c|}
\hline \multirow{2}{*}{ DEFECT } & \multicolumn{6}{|c|}{ DAY } & \multirow{2}{*}{ TOTAL } \\
\hline & 1 & 2 & 3 & 4 & 5 & 6 & \\
\hline Scumming & 52 & 48 & 54 & 58 & 47 & 44 & 303 \\
\hline Ghosting & 65 & 57 & 48 & 72 & 64 & 55 & 361 \\
\hline unRegister & 48 & 50 & 56 & 46 & 45 & 49 & 294 \\
\hline Set-off & 54 & 48 & 64 & 59 & 67 & 57 & 349 \\
\hline $\begin{array}{l}\text { Cetakan } \\
\text { tidak tajam }\end{array}$ & 55 & 50 & 48 & 45 & 58 & 46 & 302 \\
\hline $\begin{array}{l}\text { Kertas } \\
\text { putus }\end{array}$ & 59 & 47 & 58 & 65 & 69 & 57 & 355 \\
\hline Total & 333 & 300 & 328 & 345 & 350 & 308 & 1.964 \\
\hline
\end{tabular}

Perusahaan menetapkan standar produk yang rusak atau waste untuk tiap kali mencetak yaitu 6\%, dari jumlah oplah sebanyak 12.500 eksemplar dalam sekali cetak. Jadi jika di hitung:

$12.500 \mathrm{eks} \times 6 \%=750$ eksemplar.

Maka dapat disimpulkan, perusahaan sudah bisa mencapai standar produk yang rusak karena jumlah waste yang dihasilkan perharinya kurang dari standar produk yang rusak yang sudah ditetapkan.

Dari tabel di atas juga dapat diartikan rata rata yang menyebabkan jumlah produk yang rusak atau waste cukup banyak dipengaruhi oleh permasalahan seperti;
Ghosting, Set-off dan kertas putus. Berikut adalah Fishbone Diagram penyebab terjadinya permasalahan yang terjadi :

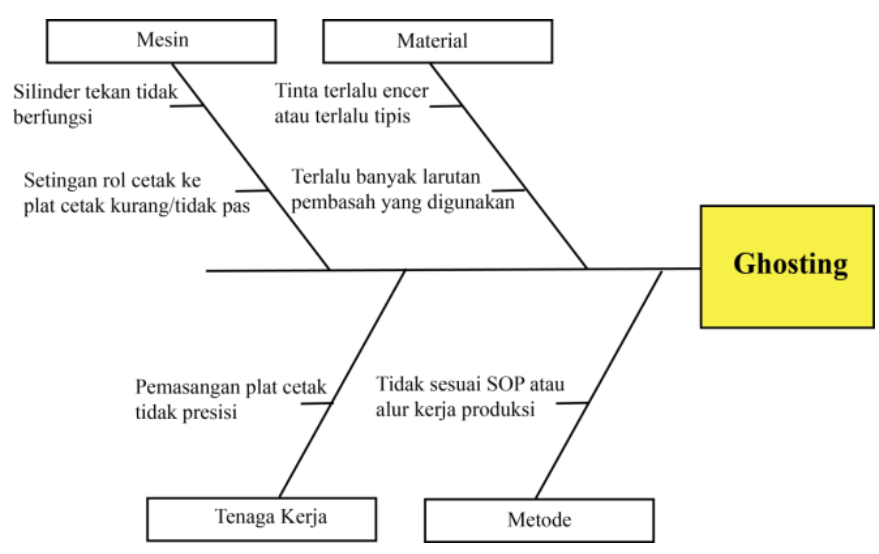

Gambar 3. Fishbone penyebab Ghosting 


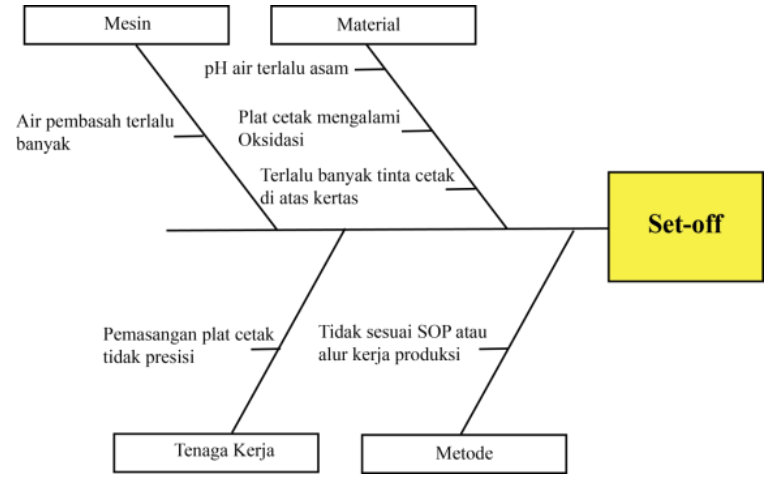

Gambar 4. Fishbone penyebab Set-off

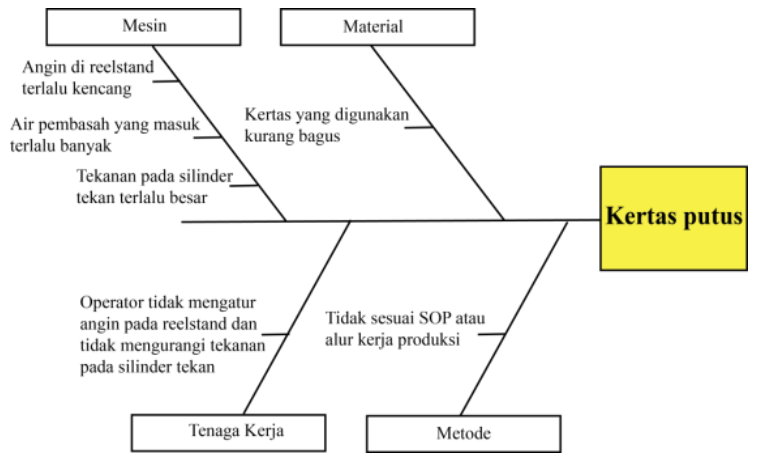

Gambar 5. Fishbone penyebab Kertas putus

B. Pengaruh Terhadap Hasil Cetakan

Pengaruh permasalahan cetak terhadap hasil cetakan yaitu cetakan menjadi tidak sesuai dengan proof yang ada. Bagian pra cetak dan cetak dapat mempengaruhi hasil cetakan, misalkan plat rusak, waktu pembuatan plat yang lama, scumming, unregister, gosting dan lain lain. Jika terus terjadi kesalahan cetak di atas maka dari itu akan membuat waste banyak. Untuk mengefesiensi serta meminimalisir waste yang didapat dan meningkatkan kualitas hasil cetak yang optimal maka diperlukan perhatian lebih dan pengendalian mutu atau quality control

\section{KESIMPULAN}

Berdasarkan pembahasan diatas, maka dapat disimpulkan beberapa hal yang berhubungan dengan penelitian ini, yaitu:

1. Hasil kualitas cetakan iklan koran Bisnis Indonesia di PT Aksara Grafika Pratama sudah baik namun masih memiliki beberapa kekurangan seperti warna tidak sesuai proof, dan sulit mendapatkan register pada saat mencetak.

2. Faktor yang menyebabkan kualitas cetakan iklan koran dan waste koran Bisnis Indonesia yang berlebihan disebabkan oleh, set-off, ghosting, dan kertas putus.

3. Mengatasi permasalahan yang mempengaruhi kulaitas cetakan iklan koran dan waste koran Bisnis Indonesia dengan cara cetak secara tipis, mengganti tinta cetak yang berkepekatan tinggi, memeriksa alat spray powder, dan mengatur volume air pembasah.

\section{REFERENSI}

Amri, L. H. A., \& Wijayanti, R. A. (2019).

Pemanfaatan Sistem Informasi

Geospasial Online Untuk Mendukung Pengambilan Keputusan Pemanfaatan Tata Ruang. Jurnal Teknologi Informasi Dan Terapan, 6(2), 62-66. 
Vol. 6, No. 2, Oktober 2019, hal. 84-95

https://doi.org/10.25047/jtit.v6i2.111

Djamara, MT. 2018. Buku Pengantar Ilmu

Grafika. Jakarta: Politeknik Negeri

Media Kreatif

Faux, Ian. 1973. Modern Lithography, London: MacDonald and Evans

Setyosari, Punaji. 2010. Metode Penelitian

Penelitian dan Pengembangan. Jakarta:

Kencana

Sudiyamto, 2010. Teori Dasar Cetak Ofset

Prodi Teknik Grafika. Jakarta:

Polimedia Publising

Suprapto, Puji. 2019. Bahan Ajaran Mata

Kuliah Cetak Web. Jakarta: Politeknik
Negeri Media Kreatif

Susanto, Eko. 2014. Pengaruh Kualitas Produk dan Harga Terhadap Keputusan Pembelian Konsumen : Studi Kasus Pada Busana Muslim Mirzani Marga Asih Bandung. Skripsi, Universitas Komputer Iindonesia Bandung.

Tio PM, M. Mujiya U. 2018. Aplikasi Seven Tools Untuk Mengurangi Cacat Produk White Body Pada Mesin Roller. Semarang: Universitas Diponegoro

Wasono, Antonius Bowo. 2008 Teknik Grafika dan Industri Grafika, Jakarta: Departemen Pendidikan Nasional. 